\title{
Play songs by children and their educational implications
}

\author{
Margaret J. Kartomi
}

In the broad enculturative process, children learn to sing and play the music of their particular cultural tradition, which is controlled by adults. In all cultures children are sung or taught songs by adults for children, including such songs as lullabies, nursery rhymes and songs of advice. Clearly distinguishable from this repertoire of songs for children, however, are songs by children. These are songs created by children at play for the purposes of the individual or group play situation. These songs are found in all cultures and they share a common approach to rhythm, formal structure, textual form and content, and performance style. They share a quality which is perhaps most aptly described as a quality of childlikeness (Kartomi 1980: 172).

Teachers who are aware of this repertoire have a rich source of musical materials upon which to build effective music teaching techniques, especially in the process of encouraging children's awareness of the basic elements of music and their native musical creativity. The educational adage 'to move from the known to the unknown' has valuable application here. When introducing children to the principles of musical rhythm, metre, form, melody, tempo, stress, dynamics and timbre, teachers can start with the songs children create themselves. By understanding the stage of creativity which particular groups of children have already reached in their play world, teachers will have a head start in introducing musical ideas which children would otherwise find quite complex.

There is evidence that children everywhere manipulate sounds naturally and creatively in the play situation. Our children are not just immature imitators of the adult world; they are both creative and imitative. As in child art, which has a unique, nonadultlike quality, child-created music has distinctive stylistic qualities all its own. This fact is well-known in the field of art, among other things through children's art exhibitions, but it is much less widely realised in the field of music. Why is this so?

Western culture art has been taught to children differently from music. In recent decades, teachers have often given children rein to draw freely according to their own childlike view of the world. Adult artists and others appreciate the results of child art in its own right as artistic expressions of the perception and imagination of childhood. On the other hand, music has tended to be taught either individually to children or in class groups. The emphasis has been on learning to perform from music notation. In group singing classes teachers have encouraged children to achieve clean entries and closures. 
Likewise, teachers of group instrumental performance have tried to produce a 'clean, balanced' ensemble sound. Adult ideals have dominated teaching methods. With a few relatively recent exceptions in the case of improvisation and other experimental music classes, little rein has been given to the musical creativity of children.

It is now becoming clear that songs by children are worlds apart from adultcreated children's music, both in their textual and musical qualities, for children select their modes of expression according to their own childlike view of the world. They have their own approach to rhythm, form, melody and performance style. Children create, reproduce and perform according to their sense of priorities as children, according to what they unselfconsciously select as important for use in the play situation and their view and experience of living. Their style of singing is also indicative of the play situation. The sweet timbre and smooth entry techniques of a boys' choir is worlds apart from the singing styles of the real play world. Children at communal play often sing in a chesty, forceful way, with great vigour. Sometimes they sing softly and meditatively, for example while doodling, drawing or thinking about something. Children are indeed imitative, but there is fecund source of musical creativity in every child. Children often create songs about their pleasant and unpleasant feelings and experiences, such as special eating treats or being 'told off' by adults. Their need to express their feelings can take the form of song creation. Sometimes the spontaneous musical wanderings of a single child catch on with other children and a song is thereby established, if only for a few days, weeks or months. Some songs created at play, however, last for years.

Texts of children's play songs are often very direct. They may express thoughts about subjects forbidden them by adults, such as sex, urine and excreta. The existence of a rich, diverse body of play songs in Australian playgrounds is shown, for example, 
in Ian Turner's Cinderella dressed in yella (1969). In this book, Turner presents texts of many play chants collected in Melbourne playgrounds, such as the song in transcription 1 (to which I have added the transcription of the rhythm to which the song is normally chanted).

Rhythmically the last line of this song, which has been sung by children in Melbourne for several years, resembles the main rhythm of a song for the game called 'chasey'. This song, which I collected in an Adelaide playground in 1968, is shown in transcription 2.

If we look into our memory of childhood, all of us can probably remember ditties like these, for they are typical of countless childlike songs found in many cultures. The ethnomusicologist Brailoiu was the first scholar to collect a body of play songs across the cultures. In his intercultural study of songs by children in Hudson Bay in Canada across to Europe, Africa and Japan, he proposed some norms of play-song style. This collection, plus songs collected by other investigators (especially from Monash University, see e.g. Kartomi 1980, Hall 1984, and Romet 1986) suggest that communities of children everywhere have their own constantly changing repertoire of child-created songs, songs which share similar textual and musical qualities. These songs may refer to particular places or people or to pleasant or unpleasant events in the children's lives, or they may refer to more general experiences or feelings. It is likely that songs of any community of children are in constant flux. For example, a repertoire of child-created Pitjantjatjara song texts sung at Ooldea (South Australia) in the late 1930s and published by R.M. and C.H. Berndt in 1940 are quite different from the child-created songs sung by the same group of people after they migrated to Yalata, an Aboriginal (Pitjantjatjara) camp and Lutheran mission station situated at the edge of the Nullarbor Plain in South Australia.

How are play songs created? How do they become established in the repertoire of songs sung by children for any length of time? In 1969, the anthropologist Isobel M. White and I went to the Pitjantjatjara camp at Yalata to study the music sung by children there (and in White's case, to study the lives of the Pitjantjatjara women). While in the bush at Yalata I occasionally left the tape recorder running in order to record sounds made by children while they were concentrating on their play activity. The spontaneous musical wanderings which I recorded gave some indication of the types of ideas which came naturally to their minds and threw some light on the nature of their creative processes. Children at play at Yalata created, improvised and eventually established their play songs in a similar way to any other play activity. Most of their musical improvisations or doodlings were forgotten immediately after the moments of creation. They consisted of original or borrowed musical thoughts based on the children's past musical and verbal experience, either in Pitjantjatjara or Western tradition or in both.

While drawing together in a group in the sand or on paper, for example, one child would sing a phrase which would be taken up, repeated and varied by other children in turn, mostly quite unselfconsciously and even absentmindedly. This is the way, I believe, that children's play songs are created. Sometimes the improvisations are remembered by groups of children and adapted into the general repertoire of play songs. Clearly only a minute portion of the total improvisational activity of children survives, even for a short amount of time. Only a very small number of improvisations 
are eventually absorbed into the body of established play song, which may often last for several years. It is my belief that children's musical doodlings pass beyond the ephemeral stage only when their rhythms are memorable and their texts express a clear commonly felt positive or negative experience of children, such as one of pleasure, pain, fear, solidarity or derision, and that these play songs are normally sung when children play together in a direct assertive fashion, such as corporate games, when eating together, during group teasing situations and on occasions demanding a team spirit. While at Yalata I was able to record a number of versions of established play songs, songs which according to Mr Albert Prater, an elder of the people at Yalata, were created by 'little children, not mothers'.

The play song texts sung at Yalata, like those in white Australian playgrounds (see Turner 1969) and elsewhere, deal with common feelings and experiences of children, and they include some 'underground songs' containing forbidden words. Two popular songs sung by children when we were at Yalata were Njakula Pumpinu and Apu. Wini both of which contain the naughty word, kuna (excreta). The text of Njakula Pumpinu translates 'I seeingly bent, excreting'. The song is especially popular among boys at play, sung with loud teasing laughter and mock pleasure at its 'vulgar' meaning. Apu Wini, on the other hand, is a serious song which may have originated from the adult repertoire, but with kuna often laughingly substituted by the children for the word apu. Apu. Wini means 'baby on a carrying dish', and the second phrase of the song means 'Ninja is telling something'. Another children's song is Pulpala Tingku, meaning 'poor fella dingo, don't steal'. 'Poor fella dingo' is a term of derision for the wild Australian dog, the dingo, which is greatly feared by the children at Yalata. Some songs describe pleasant experiences dealing with food, of which there is on a whole a limited variety at Yalata. For example, the song Maralinyganja describes a rare treat which occasionally offered itself to the children and adults when 'white army people', moving down the Ooldea Road from the erstwhile military establishment at Maralinga, used to pause to drink at the water tanks and gave the Aborigines tomatoes to eat. As a result, they began to associate Maralinga with good food and the children created a song with a mixed Pitjantjatjara-English text which means 'at Maralinga, good place, nice place for eating'.

However, the most popular play song at Yalata in 1969, which was sung almost interminably by the children, was Wi:tpikspa, a song about the breakfast cereal Weetbix which is eaten after being dipped in an empty can or pannikin (panikinta) of tea. The main utensils used in the area are empty cans, and tea is the most common drink for all age groups. Another song, Pupuntu, expresses the children's feelings of solidarity for the boy, Pupun, when he was in trouble with the adults. The origin of the song was recounted to us several times by children and adults at Yalata, who said that it was created by Pupun's friends. One of the children translated the text as 'Pupun borrowed a tyre', thus offering the less negative word 'borrow' in place of the emotive word 'steal'. Pupun 'got into trouble' for 'borrowing' a tyre marking an airstrip at Yalata at the time of an expected plane landing. The song reflected the children's sympathy for Pupun, who was severely reprimanded by the white adults.

The style of these play song texts possesses the universal childlike characteristics of brevity, repetitiveness, directness of sentiment and humour. They have a contemporary quality, unlike the mainly religiously and historically oriented texts of the adults' 
and children's ceremonial song repertoire and the soothing texts for lullabies. The straightforward, relatively unsubtle nature of most of the play song texts partly determines their musical characteristics as a song type. The texts also reflect the bilingual situation at Yalata.

What are the unique characteristics of child-created music? As has been intimated above, Brailoiu was the first scholar to present a theory about the universal rhythmic characteristics and formal tendencies of songs by children. He proposed the hypothesis that the rhythmic, metrical and formal-textual qualities of songs by children are based on four main rhythmic models and their variants. (Only three of the models are relevant to my Yalata song collection; thus the fourth model is not discussed here.)

Brailoiu asserted that songs by children tend to consist of lines with a duration of eight quaver beats, either joined two by two (Model 1), or joining two crotchets and two pairs of quavers (Model 2), or joining four crotchet beats (Model 3). They are typically in binary rhythms, like children's footsteps, though some have alternating binary and ternary rhythms. Most play songs consist of one or more series of eight syllables each, although some consist of shorter or longer series. Where an eight-beat consists of less than a value of eight quavers, rests substitute for notes, thus bringing the series' total durational value to eight quavers. Such a series is said to be truncated (as in the second bar of the song I collected in Melbourne, 'Red Top taxi, you're not he.') Other series are extended from the normal eight to a total value of, say, ten quavers, as in Njakula Pumpinu (see below). Since Brailoiu's Model 1 uses only one recurring time value (i.e. quavers) it is termed 'isochronic.' Model 2, on the other hand, is termed 'heterochronic', as it consists of a pair of crotchets and two pairs of quavers arranged in a variable, paired sequence. Model 3, based on a series of four crotchets, is, of course, isochronic Brailoiu's bar-lines mark word repetition, assonance and syntactic parallels and his dotted bar-lines show the metric pulse, usually in pairs of quaver beats.

As it turns out, the two Australian playground songs I transcribed fit his theory well, as do a number of Aboriginal Australian play songs collected at Yalata, South Australia in 1969, and as do virtually all songs by children that I have encountered. Some, however, consist of four series of eight quavers, with an added semiquaver in the fourth series, followed by a series comprising four crotchets (which may, however, be freely added to in the playground situation according to the whim of the children at play).

Thus the play chant 'Red Top taxi, one, two, three; Red Top taxi, you're not he' resembles the rhythm of the second series of the famous Anglo-American play chant 'Eeney meeney miney mo, catch an Indian by the toe'. It also resembles the second series of a popular play song that I recorded at Yalata, called Wi:tpikspa (Song 1), namely panikinta narinji. The first series of Wi:tpikspa, on the other hand, is Brailoiu's Model 3 (the truncated version, called Type 22). As in most play songs, the series of the Wi:tpikspa song are repeated many times, either singly or in alternation with each other.

Like Wittpikspa, the strictly binary-metered song, Pupuntu opens in the transcription shown below with a series (Model 2, Type 22) which is established by a slightly varied repeat and is followed by another series: taia tjilamanu. This is also repeated. After which the singer restates the original series. The song consists of five series, each 

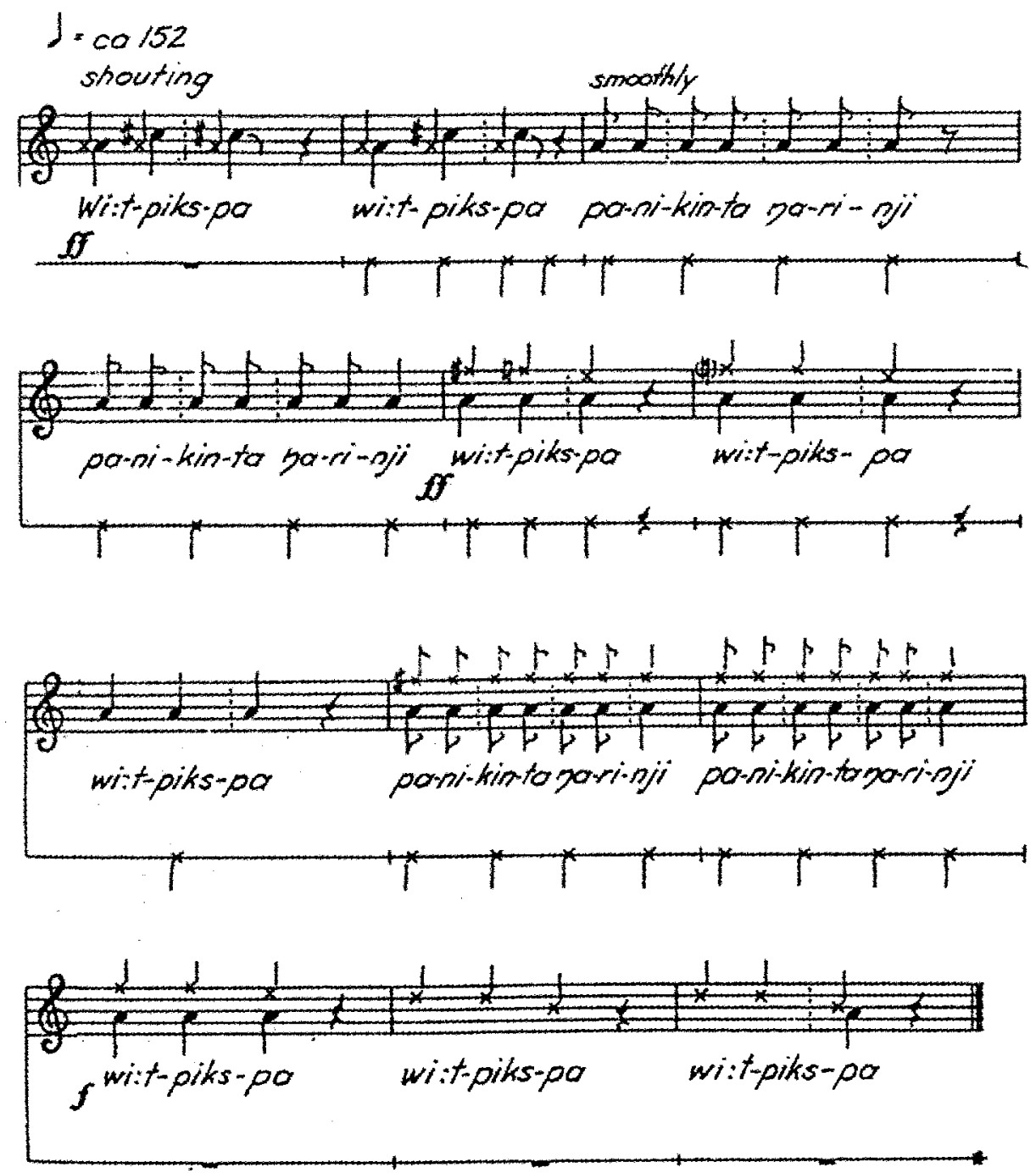

Transcription 3: Wi:tpikspa, Version 1 

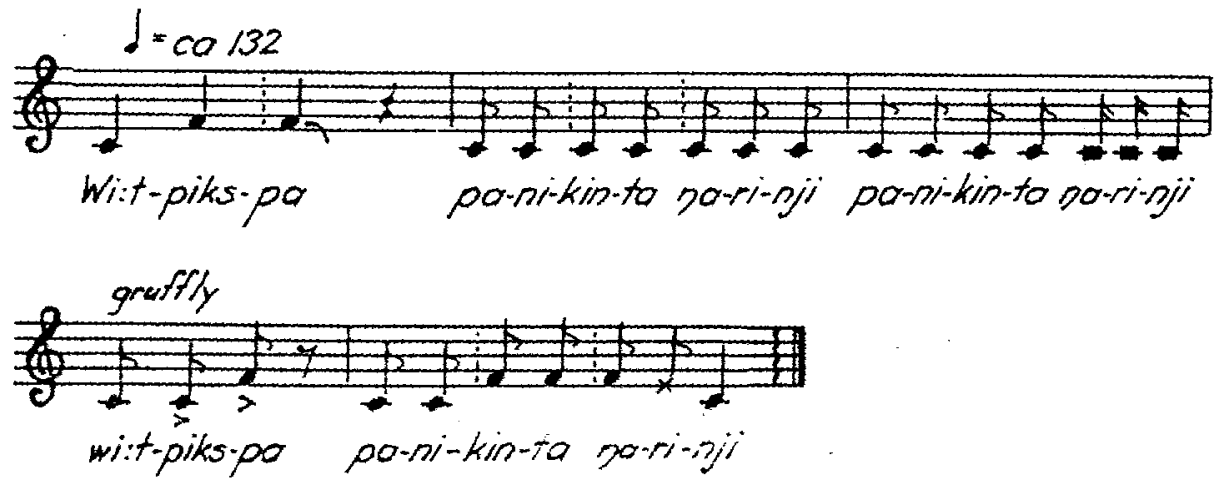

Transcription 4: Wi:tpikspa, Version 2
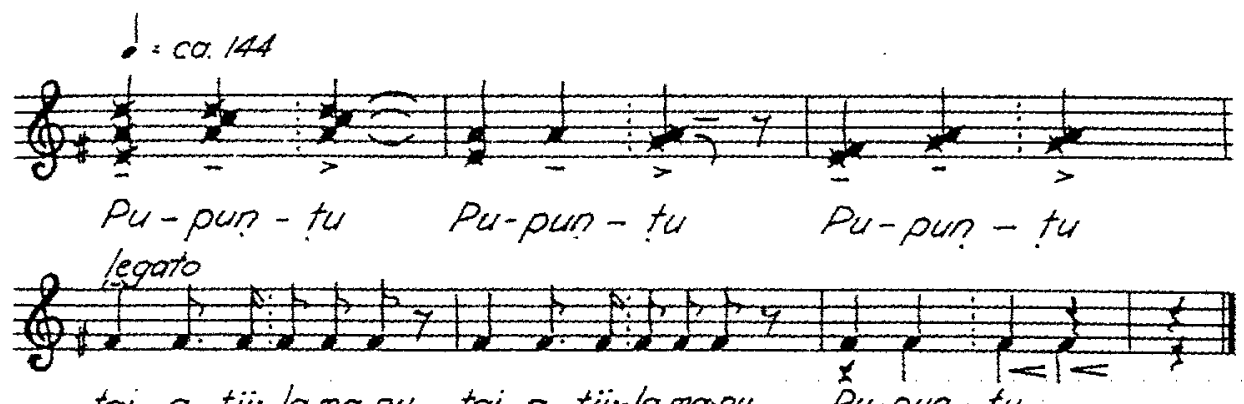

tai-a tii-lamand toina tji-lomanu pu-pun-tw

$$
P_{U}-p o n-f_{0}
$$

Transcription 5: Pupuntu

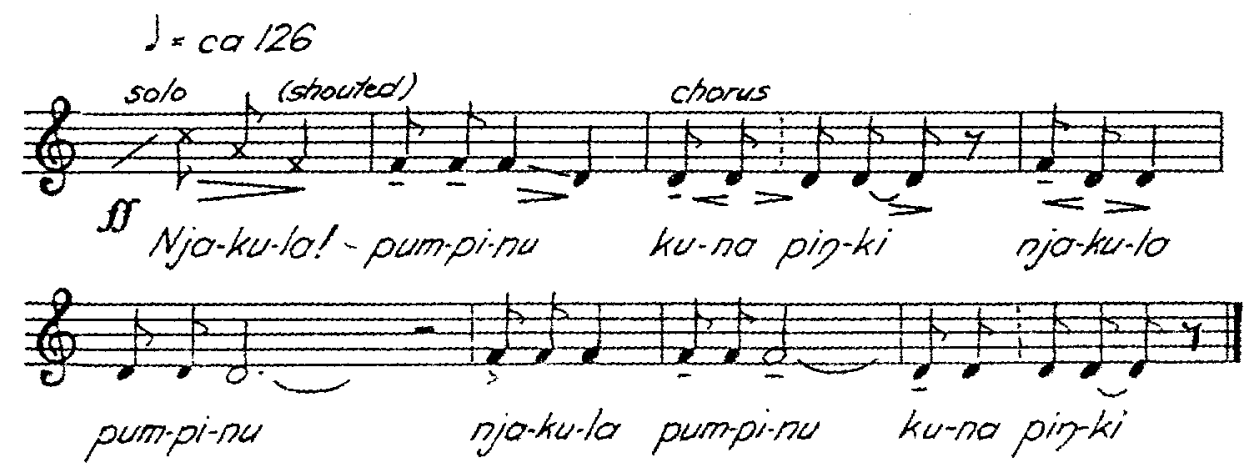

Transcription 6: Njakula Pupuntu 


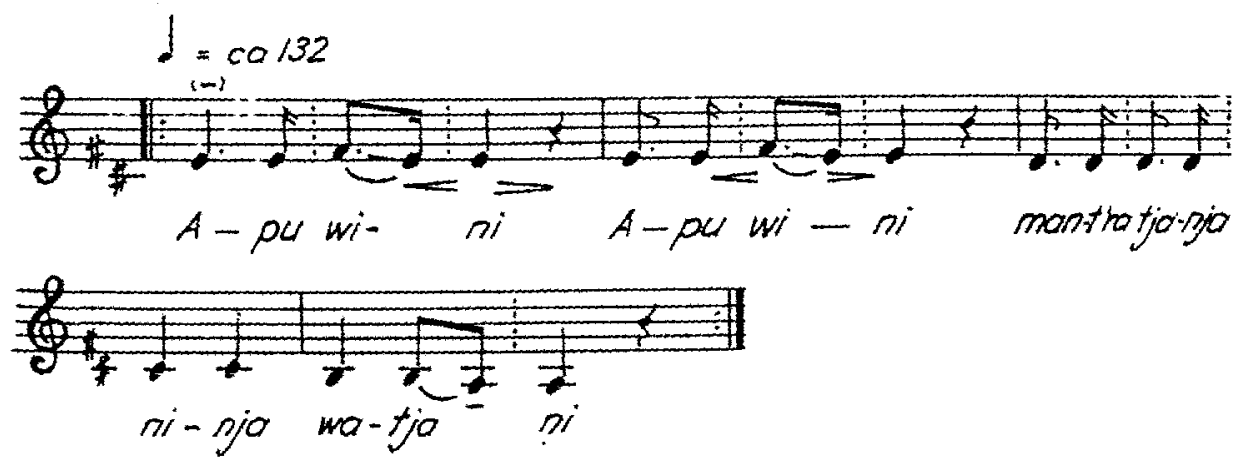

Transcription 7: Apu wini

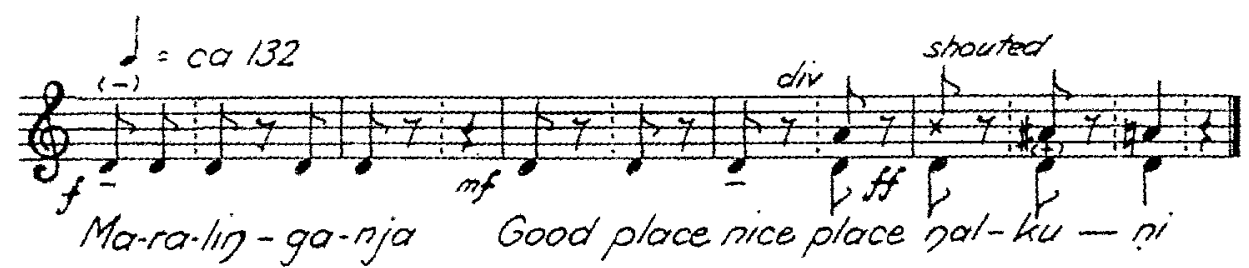

Transcription 8: Maralingganja 
of eight quavers in duration, and the formal structure of most performances is the repeatable $a a b b a$ (see Transcription 5).

Njakula Pumpinu consists of five non-equal heterochronic lines averaging eight quavers in length. All series are performed, however, in truncated or extended form (see Transcription 6).

The first line is an extended variant of Brailoiu's Model 3 (Type 23), repeated twice, whereas the second line resembles one of the truncated Model 1 examples. The formal structure of the song varies in performance, but it always alternates between the formal structures of $a b$ and $a a b b$, where $a$ is the duple plus triple or sextuple metric first line and $b$ is the triple-metric second line.

Apu Wini is also based on the formal principle of alternation between and repetition of two rhythmic series, $a$ and $b$, but its overall formal structure is always $a a b$, which may be repeated as many times as the children wish. The song resembles play songs in other parts of the world by virtue of its eight-quaver series, its short repeated first line, its childlike shouted manner of performance, and the amusing substitution of the word kuna, meaning 'excreta', for apu (see Transcription 7).

The first and second lines are 'skipping-rhythm' versions of one of Brailoiu's Model 2 models (i.e. Type 10), while the third line is a complete instance of the same, and the fourth resembles his Model 3 (Type 22).

The short play song, Maralinganja also possesses child-like structural qualities. Its first line is an extended series performed in irregular metre often with a lingering third syllable in the structure, $a b b$. See Transcription 8 .

However, the second and third series, based partly on English words, are chanted in straightforward duple metre with the third line being a truncation version of the second. The first series is an extended version of Brailoiu's Model 1.

The main element of musical variability in these child-created songs is the formal structure. All the play songs are based on two short contrasting rhythmic motifs or series, each of which may be repeated and alternated with the other in regular or irregular sequence. Thus a song may have a different formal sequence each time it is performed. The rhythmic motifs are associated with definite melodic ideas, but these are highly variable in performance. The play songs are generally based on two musical ideas which alternate in regular or irregular fashion. Two basic types of metre are used. Some songs are in strict duple metre, namely Pupuntu, Apu Wini, Wi:tpikspa and Maralinganja except when it lengthens the syllable nya. The other songs alternate regularly or irregularly between duple and triple metre.

The melodic line in the play songs is variable, being subservient to the rhythmic characteristics. Different versions of the one text may have quite different melodic features. Melodic range in the songs tends to be quite small. Monotone chanting occurs in most of Wi:tpikspa (Transcription 3), Maralinyganja and Pupuntu. Bitonal chanting is to be found in parts of Pupuntu and Njakula Pumpinu. Sextonal singing occurs in Apu Wini. A tetratonal version of Wi:tpikspa is shown in Transcription 4 . Sometimes songs are shouted at free pitch. Excluding shouted tones, the widest melodic range among the songs I recorded was 900 cents in Apu Wini and an octave in one version of Wi:tpikspa. 
Most of the songs have a prevailing descending direction of melodic movement, where the pitch of the initial tone is the highest of the range and the pitch of the last tone is the lowest. Exceptions include most of the Wi:tpikspa versions and the monotone chants (which I recorded but have not included here). Most songs have a high amount of tonal repetition and a fairly low degree of melodic direction change. Half tones are rare in these play songs, unlike in the adult music. Most of the songs are chanted loudly in chorus with very loud, indefinite-pitched shouting on some syllables. Tonal variability between shouted versions of the same song is quite marked, but usually with the same rhythm and accentual patterns. Rhythm and accent are primary; melody is secondary.

Metric accents generally occur on the first syllable of the word as in most children's play songs over the world, but this is only to be expected in Pitjantjatjara songs as the first syllable is normally stressed in the language anyway. However, the position of accents is irregular in many performances. When little girls or boys are at play they sing softly or whisper well-known play songs with little or no stress at all. On joining in with a group of children in loud singing, on the other hand, they often perform strong accents on different notes each time they sing.

\section{Conclusions}

Teachers wanting to promote and encourage children's musical creativity in the classroom may find it valuable to start from the children's own play song world, modifying the adult-derived methods of teaching and adopting a more child-centric one, observing them at play (see Corsaro 1985), and fully exploiting the sources of their musical creativity as they teach them about the principles of music and to perform songs of the adult repertoire. Music education begins at a very young age and it occurs willy-nilly outside the classroom as well as within it.

Not all songs by children are, or should be, accessible to adults for, as we have noted, children have their own underground songs which they do not want adults to hear. It is fascinating to come across such songs in one's own backyard. Yet surely adults should not seek out such knowledge; on the contrary they should allow children the privilege of keeping these songs to themselves and to use them as an emotional outlet. However, an increased awareness by adults of these and other products of children's musical creativity only serves to assist teachers in the continual search for new creative approaches to the teaching of music to children.

In many ways, the play songs which I recorded at Yalata have more in common with play songs in other parts of the world than they have with the music of the adult Pitjantjatjara community. This is despite the fact that the children begin to be enculturated into the adult traditions when they are very small. Child-created play songs at Yalata have little in common with the soothing, ornamented descending melodies sung to infants and the religious and legendary songs of the adult tradition which are absorbed by children on story-telling and ceremonial occasions.

Two main conclusions about the nature of childhood and its music may be drawn from this study. 
Firstly, children are not just little people learning to become adults. They have sets of values of their own, which are expressed in and expressive of both communal and individual play situations. They include certain unique musical attitudes and preferences.

Secondly, children's play songs exist as an identifiable musical type. Though partly derived from or influenced by adult cultures, these songs have been shaped by children according to their own outlook, experience and purposes in the play situation. The typical sound of children singing at play is a rather chesty, forceful sound, characterised by ragged entries, uneven texture, energetic even raucous dynamics, and a vigorous, animated atmosphere. Children's music is in a continual process of change, both in the minute musical details of performance and in the larger matter of repertoire which indicates that creativity is an ever-present factor in children's music.

\section{Acknowledgments}

My fieldwork at Yalata, carried out together with Sally While, was made possible by the cooperation and assistance of the Pitjantjatjara and the white populations of Yalata, and by a senior research fellowship and field assistance from the Australian Institute of Aboriginal Studies. I acknowledge the considerable assistance, advice and friendship of Sally White both in the field and afterwads.

Margaret Kartomi is a musicologist who has worked among Indonesian and Australian Aboriginal communities. She is Professor of and Head of Music at the Monash University, Melbourne.

\section{References}

Berndt, R.M and Berndt, C.H. 1940 'A preliminary report of field work in the Ooldea Region, western South Australia.' Oceania bound reprint XII/4, XIII/1-4, XV/1-3.

Brailoiu, Constantin. 1954 'Le rythme enfantin', Colloques de Wegimonts, Cercle International d'Etude Ethnomusicologique, Brussels: 64-96 (English translation in Brailoiu, C., Problems of ethnomusicology, Cambridge University Press.

Corsaro, W.A. 1985 'Entering the child's world: research strategies for studying peer culture', in Friendship and peer culture in the early years. Ablex Publishing Corporation, New Jersey.

Hall, Hazel. 1984 Study of the relationship between speech and song in the playground rhymes of primary school children. PhD thesis, Monash University [Melbourne].

Kartomi, Margaret J. 1973 'A children's ceremony at Yalata', in The Australian Aboriginal Heritage, R.M. Berndt and E.S. Phillips (eds), Ure Smith, Sydney.

Kartomi, Margaret J. 1980 'Childlikeness in play songs - a case study among the Pitjantjara at Yalata', Miscellanea Musicologica, Adelaide, 11: 172-214.

Romet, Cheryl. 1986 Children's play songs in the Priangan, West Java. MA thesis, Monash University [Melbourne].

Turner, I. et al. Cinderella Dressed in Yella Heinemann, Melbourne.

Original copies of my field recordings made at Yalata, South Australia, in 1969 are held at the Australian Institute of Aboriginal and Torres Strait Islander Studies in Canberra and the music archive of the Department of Music at Monash University, Melbourne. 